\title{
trames of reference of two committees of the Scientific and Technological Activities Commission
}

The Council at its meeting on 16 January $1977^{1}$ voted to approve the frames of reference for two new committees of the Scientific and Technological Activities Commission. The frames of reference for these STAC committees are given below.

\section{Committee on Atmospheric and Oceanic Waves and Stability}

The earth's atmosphere and oceans sustain a rich variety of oscillatory, wavelike motions including Rossby and planetary waves, tides, semiannual and quasi-biennial oscillations, Kelvin and Yanai waves, inertial oscillations, internal and surface gravity waves, capillary waves, and acoustic waves, as well as hybrids of these. The waves are not merely striking features of observed geophysical motions; they are meteorologically significant as well. For example, Rossby and planetary waves are important elements in global energy and momentum budgets, in addition to producing the familiar pressure highs and lows of temperate-latitude weather. Mesoscale gravity waves on occasion trigger severe convective storms. The focus of the Committee on Atmospheric and Oceanic Waves and Stability is the fundamental physics governing wave generation and propagation rather than direct application; however, it does remain aware of such applications of wave research for weather forecasting on all scales. Sometimes the wave state of the atmosphere and oceans is itself of interest to the committee. For instance, through their generation of clearair turbulence and their effect on sea state, small-scale waves have a direct impact on commercial aviation and shipping in addition to their cumulative dynamical effect on larger circulations.

The Committee on Atmospheric and Oceanic Waves and Stability serves the Society primarily by 1) remaining abreast of developments in geophysical fluid wave research as they affect other areas of meteorological activity, 2) fostering communications among wave researchers from both atmospheric and oceanographic disciplines, and 3) furthering information exchange between wave researchers and other elements of the meteorological and oceanographic communities. To do this, the committee prepares or supports publication of papers and surveys in the Society's journals and organizes conferences, symposia, and workshops, sometimes in cooperation with other committees of the Society and other organizations. As the need arises, it represents the Society and helps coordinate research planning and programs in this research area.

\section{Committee on Meteorology of the Coastal Zones}

The growing interest of meteorologists in problems of the coastal zone has been a direct response to contemporary societal problems, the national emphasis on coastal zone management, and the development of offshore resources. These are further augmented by increased requests for clearer understanding and descriptions of coastal processes by scientists in sister disciplines.

Several clear obstacles are emerging that restrict the extent of our scientific response to some critical societal requirements. These obstacles encompass inadequate states of the science, logistics, data, and in some cases merely the need for the consolidation of current technology. All could be alleviated to some extent by improved exchange between the participating scientists. A primary objective of the committee is to facilitate this exchange. The committee assumes responsibility for:

1) promotion of a better exchange between coastal scientists through planning and support for appropriately scheduled meetings, workshops, and seminars;

2) advising the Society on problems related to meteorology of the coastal zones;

3) coordination through the Society requirements of coastal zone meteorology development with national and local agencies.

The committee focuses on a specific meteorological environment and draws upon substance from nearly all the meteorological subdisciplines, as well as several sister disciplines. The committee will define specific problem areas with the proper balance of commonality, significance, and problem vulnerability. Three problem areas that the multidiscipline coastal scientists face in common are:

1) the discrete mesoscale processes that are unique products of the triple-point intersection of the airland-sea boundaries;

2) inherent sparcity of offshore data required to resolve the mesoscale features;

3) the interdisciplinary nature of the societal problem to be served, as well as the interdisciplinary approaches to the solutions.

1 See "Minutes of the Council," page 427, \15. 


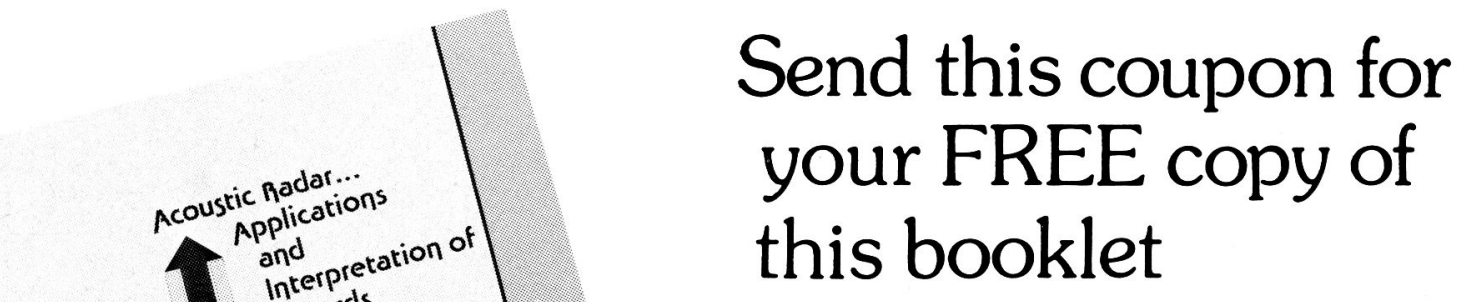

ACOUSTIC RADAR

"APPLICATION AND INTERPRETATION OF RECORDS"

Name

Address

City

State Zip

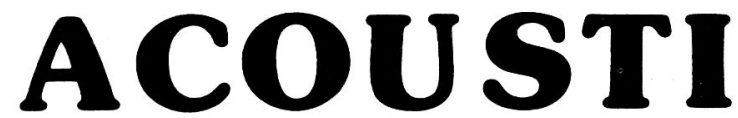

Current users of this simple-to-operate, moderately priced instrument include-

Powerplants

Smelters

Consulting firms

Government laboratories

Universities

throughout the world.

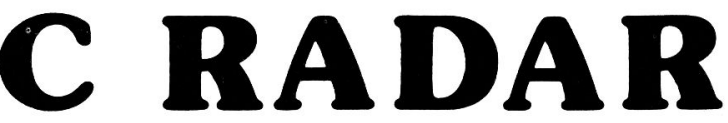

The instrument is being used for-

Environmental impact studies

Real-time emissions control

Diffusion research

Synoptic and mesometeorological research.

Turbulence levels and studies

Time interpolation of sonde data

Continuous remote sensing and recording of-

- INVERSION HEIGHTS AND THE DEPTH OF THE MIXING REGIONthe capability of the atmosphere to disperse pollutants

- THE DIURNAL PATTERN OF NOCTURNAL LAYERING, MORNING BREAKDOWN OF INVERSIONS, AND THE DAYTIME GROWTH OF CONVECTIVE CELLS-their timing and strength for air pollution forecasting and analysis
- WAVE MOTIONS AND BREAKDOWN, FRONTAL SURFACES, AND MARINELAYER INVERSION-for operational meteorology and research

- HEATED PLUMES FROM SMOKE STACKS-a direct measurement of plume rise

- THE TOP OF A LAYER OF FOG OR LOW CLOUDS-an operational tool for airports

\section{AEROVIRONMENT INC. 145 VISTA AVE., PASADENA, CA. U.S.A. 91107 • 213-449-4392}

